\title{
LINE-ELEMENT FORMULATION FOR UPHEAVAL BUCKLING ANALYSIS OF BURIED SUBSEA PIPELINES DUE TO THERMAL EXPANSION
}

\author{
Ji-Hui Ning ${ }^{1}$, Si-Wei Liu ${ }^{2}$, Jian-Hong Wan ${ }^{1}$ and Wei Huang $1,3 *$ \\ 'School of Civil Engineering, Sun Yat-Sen University, Guangzhou, China \\ ${ }^{2}$ Depatment of Civil and Environmental Engineering, The Hong Kong Polytechnic University, Hong Kong, China \\ ${ }^{3}$ Southern Marine Science and Engineering Guangdong Laboratory, Zhuhai, China \\ * (Corresponding author: E-mail: huangw288@mail.sysu.edu.cn)
}

\section{A B S T RA C T}

Subsea pipeline is the critical component in the offshore systems for transporting oil and gas from resource sites to ports Its structural failure will be a disaster of heavily polluting the environment leading to unpredictable losses. The mediums inside subsea pipelines are conventionally heated in service for easier transporting after increasing fluidity, resulting in accumulative thermal expansion of the pipeline to induce thermal expansion, triggering upheaval buckling. It is crucial when designing subsea pipelines but always challenging to evaluate rigorously because of the complexities in such consideration. A pipeline might length for miles, while the numerical analysis model using conventional solid finite elements is huge in computational expense, making the successful analysis very time-consuming. This research innovatively develops a new line element, namely the pipeline element, featuring the explicit considerations of soil-pipe interactions and thermal expansion. This element is numerically efficient by eliminating modeling buried soils. The element derivation procedure is elaborated with details, while a Newton-Raphson typed numerical analysis procedure is proposed for nonlinear analysis of pipelines subjected to thermal expansion. An Updated-Lagrangian description is employed for facilitating large deflections. Three groups of examples are provided to demonstrate the numerical robustness of the proposed method. Finally, a case study is given to identify the vital influential factors to the thermal upheaval buckling of pipelines.
A R T I C LE H IS TORY

$\begin{array}{ll}\text { Received: } & \text { 11 April } 2021 \\ \text { Revised: } & \text { 21 May 2021 } \\ \text { Accepted: } & \text { 21 May 2021 }\end{array}$

\section{K E Y W O R D S}

Line element;

Upheaval buckling;

Subsea pipelines;

Numerical;

Buckling

\section{Introduction}

Subsea pipelines are usually buried by shallow soils to avoid environmental damages in terms of water scouring, corrections and ocean sea creatures attacking etc[1,2]. However, it is more likely to accumulate heats along with the lengthening of the pipeline when it is buried by soils that may cause the cumulative thermal expansion to trigger buckling [3]. This phenomenon is named upheaval buckling [4-6], as illustrated in Fig. 1, which is critical for designing subsea buried pipelines. Nevertheless, such design consideration is sometimes difficult because it is significantly affected by several crucial factors, including the initial out-of-plumpness of pipelines, the depth of buried soils, and the tightness of seabed etc., leading to the rigorous analysis of upheaval buckling difficult. This topic has gained continuous attentions and studied by several researchers for a decade [7-11], which is still popular up to date.

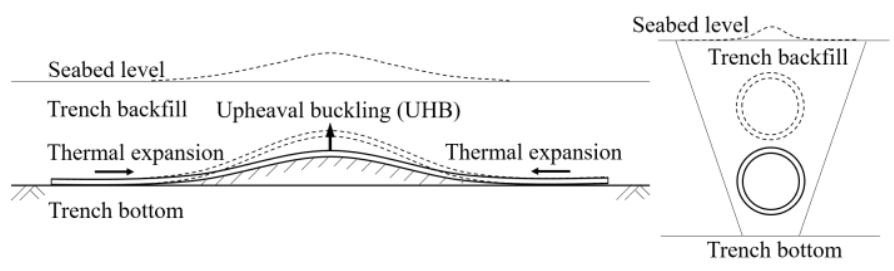

Fig. 1 Upheaval buckling of a buried pipeline by the cumulative thermal expansion

Experiments on studying subsea buried pipeline buckling have been initiated in the mid-1990s. For example, Maltby and Calladin [12,13] constructed a small-sized model for investigating upheaval buckling of buried pipelines and proposed a refined Gurson-Tvergaard-Needleman (GTN) model for theoretical analysis. Slightly later, Taylor and Tran [14] investigated the isolated prop and contact undulation imperfection topologies for determining their influences on in-service buckling of buried pipelines. Armaghani et al. [15] studied the buckling of pipelines affected by the soil reinforcement on resisting the uplift of buried pipelines. Schaminee [16] carried out full-size physical tests on buried pipelines to reveal the mechanisms of pipeline upheaval buckling. Karampour and Albermani [17] examined the propagation buckling, pure bending and buckle interaction in subsea buried pipelines. Recently, Vazouras et al. [18] executed a parametric physical test on studying the influential factors that affect buckling of sea pipelines in service. Through these experimental investigations, the dominant factors affecting upheaval buckling of buried pipelines due to thermal expansion are identified: embedment depths, pipeline geometries, and relative densities and stiffnesses of buried soils.

Besides conducting physical tests using the scaled-down models, several simplified computational methods are proposed based on the idealized assumptions. Hobbs [19] adopted an elastic Euler-Bernoulli beam to study lateral and upheaval buckling due to environmental temperature change and the tube pressure and provided an analytical solution. Shortly after, Taylor and Gan [20] proposed a calculation method to study the upheaval buckling behavior of submarine pipelines with structural imperfections and deformation-dependent axial friction resistance, providing more rational predictions than the previous mathematical methods using idealized pipelines. Ju and Kyriakides [21] investigated the upheaval buckling due to thermal expansion by including a rigid foundation with small, initial geometric imperfections through their derived formulations. Ballet and Hobbs [22] conducted studies for the asymmetric buckling of pipelines due to thermal expansion by solving the partial differential equations. Recently, by establishing mathematical models, Wang et al. [23] studied the upheaval buckling behavior of submarine pipelines with a free span. These methods are based on empirical assumptions with certain limitations for practical use, leading to the design of pipelines usually over-conservative.

Although the pipeline's structural form is simple, the accurate analysis for its upheaval buckling is usually complicated. The full length of a pipeline is difficult to be included in the analysis model to reflect the cumulative thermal expansion. Thereby, some semi-empirical design methods have been proposed, such as Palmer et al. [24] and Friedmann and Debouvry [25], to simplify the analysis problems, where the buckling length is empirically defined via the experimental tests. This design method has been extensively used up to date, but it is sometimes difficult to be executed since the buckling length is hard to be assumed accurately. Therefore, the advanced Finite-Element Analysis (FEA) method using sophisticated shell and solid elements [26-28] is employed to tackle such an analysis problem of accurately identifying the upheaval buckling of pipelines to thermal expansion.

FEA method using shell and solid elements is generally considered one of the most accurate approaches to analyze upheaval buckling of buried subsea pipelines. Pipeline and its surrounding soils are modeled by fine-meshed solid and shell elements, as shown in Fig. 2 (a). Several researchers have used this method to study upheaval buckling of buried subsea pipelines. For example, Klever et al. [29] proposed dedicated FE models for analyzing the upheaval buckling response of submarine pipelines. Zhang et al. [30] studied the upheaval buckling behaviors of pipeline segments with different Out-of-Straight (OOS) and different imperfection shapes. Robert and Thusyanthan [31] introduced a well-constructed FE model for investigating the uplift mobilization of buried pipelines in sands. Xu and Lin [32] established a sophisticated solid element model for exploring the initial stress influences on the upheaval buckling. Chen et al. [33] constructed a FE model to study the thermal upheaval buckling of pipelines considering topographic step imperfections. Liang et al. [34] employed the FEA method to study the upheaval behavior of surface-laid subsea pipelines on a sunken seabed. Their studies indicate the difficulties when using 
the FEA method for practical design because the enormous computational expense makes the FEA methods mainly limited to research applications. Moreover, the number of cases is usually enormous considering the complicated combination of environmental loads in the engineering application, which is similar as the mooring design (Stanisic et al. [35]). Therefore, it brings an urgent need to develop an efficient FEA method applicable to design large scale pipeline systems in offshore engineering.
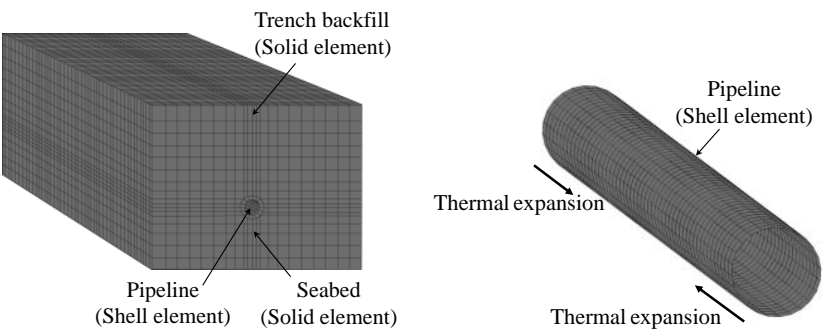

(a) Solid and shell elements modeling method

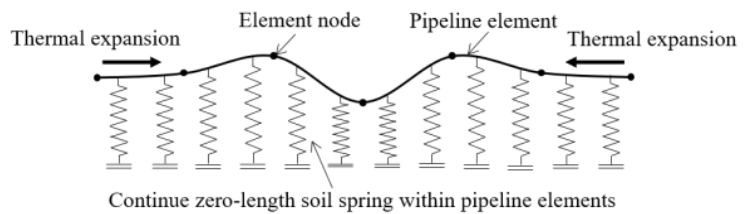

(b) Proposed pipeline element modeling method

Fig. 2 Two different finite element modeling methods

Against the background, this research derives a pipeline element (see Fig. 2 (b)), featuring by the explicit consideration of soil-pipe interactions and considering thermal expansion at the evaluated temperatures, which is numerically efficient by eliminating sophisticatedly modeling buried soils and pipe sections. The element derivation procedure is elaborated with details, while a NewtonRaphson typed analysis procedure is proposed for nonlinear simulation of a pipeline subjected to thermal expansion. An Updated-Lagrangian description is employed for determining the equilibrium conditions according to the last known status for facilitating large deflections. Three groups of examples are presented for demonstrating the analysis accuracy and robustness of the proposed method. Finally, case studies are given to examine the influential factors that affect the upheaval buckling of pipelines.

\section{Assumptions and definitions}

Based on the Euler-Bernoulli assumption, a pipeline element is derived by considering soil stiffness and thermal expansions. The following assumptions are made in the present study, which should not certainly be limited to its practical application. These assumptions are given by: (1) conservative loads are assumed; (2) strain is small, but the deflection can be arbitrarily large using the Updated-Lagrangian (UL) description; (3) surrounding soils are represented by the Winkler-typed springs without the interactions among soil springs; (4) thermal expansion is considered accumulatively; (5) the equilibrium conditions are determined based on the deformed shape; and (6) planar analysis is executed for considering buckling at one-direction, while the spatial analysis method will be presented in the coming research.

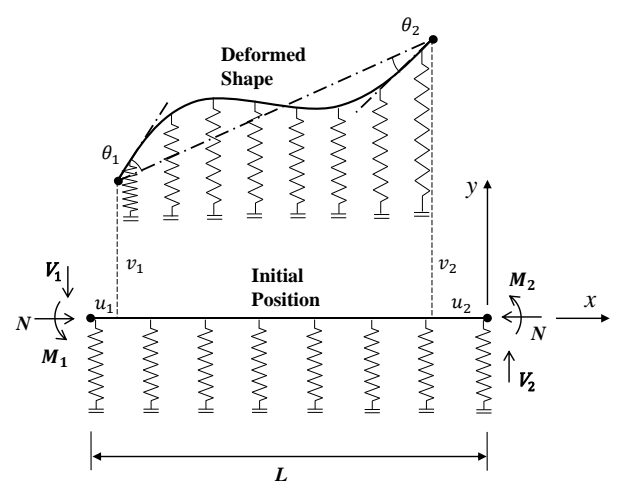

Fig. 3 Forces and degree of freedoms within a pipeline element

\section{Line element formulation}

Line element formulation is efficient in numerical analysis by condensing a three-dimensional entity into a one-dimensional model that reflects the structural behaviors along the member length. Conventional line element only simulates structural member that needs to be improved for properly analyzing a subsea buried pipeline, where the soil stiffness and thermal expansions are to be considered. This paper adopts the Euler-Bernoulli assumption and formulates a new line element, namely the pipeline element, for representing the structural properties of a subsea buried pipeline by integrating the continuous soil springs along the member length in the element formulations, as illustrated in Fig. 3. The corresponding element formulations are derived with details and presented in this section.

\subsection{Element forces and deformations}

The pipeline element's axial and lateral deformations along the element length can be described by the following interpolating polynomials,

$$
\left\{\begin{array}{l}
u(x) \\
v(x)
\end{array}\right\}=\left[\begin{array}{cccccc}
\delta_{1} & 0 & 0 & \delta_{2} & 0 & 0 \\
0 & \delta_{3} & \delta_{4} & 0 & \delta_{5} & \delta_{6}
\end{array}\right]\left\{\begin{array}{llllll}
u_{1} & v_{1} & \theta_{1} & u_{2} & v_{2} & \left.\theta_{2}\right\}^{T}
\end{array}\right.
$$

in which, $u(x)$ and $v(x)$ denote the displacements along the element's $x$ - and $y$ - axes, respectively; $u_{1}$ and $u_{2}$ represent the nodal translations along the $x$-axis $v_{1}$ and $v_{2}$ describe the nodal movements along the $y$-axis; $\theta_{1}$ and $\theta_{2}$ are nodal rotations at the element ends; and the coefficients $\delta_{1}$ to $\delta_{6}$ are expressed as,

$\delta_{1}=1-\frac{x}{L}$

$\delta_{2}=\frac{x}{L}$

$\delta_{3}=1-\left(\frac{x}{L}\right)^{2}+2\left(\frac{x}{L}\right)^{3}$

$\delta_{4}=x-\frac{2 x^{2}}{L}+\frac{x^{3}}{L^{2}}$

$\delta_{5}=3\left(\frac{x}{L}\right)^{2}-2\left(\frac{x}{L}\right)^{3}$

$\delta_{6}=-\frac{x^{2}}{L}+\frac{x^{3}}{L^{2}}$

in which, $L$ represents the length of an element and $x$ is the coordinate in the $x$ axis.

The strain tensors can be expressed according to the Green-Lagrangian strain description, and given as,

$\varepsilon_{x}=\varepsilon_{x}^{L}+\varepsilon_{x}^{N}+\varepsilon_{t h}=\frac{\partial u(x)}{\partial x}-y \frac{\partial^{2} v(x)}{\partial x^{2}}+\frac{1}{2}\left(\frac{\partial v(x)}{\partial x}\right)^{2}+\alpha \Delta t$

$\varepsilon_{x y}=\varepsilon_{x y}^{N}=-\frac{1}{2} \frac{\partial u(x)}{\partial x} \frac{\partial v(x)}{\partial x}+\frac{y}{2} \frac{\partial^{2} v(x)}{\partial x^{2}} \frac{\partial v(x)}{\partial x}$

in which, the superscripts $L$ and $N$ are representing the linear and nonlinear portions, respectively; $\varepsilon_{x}$ is the normal strain; and $\varepsilon_{x y}$ is the shear strain in the $x-y$ plane. $\alpha$ denotes the thermal expansion coefficient; while, $\Delta t$ is the temperature difference.

The following relation is expressed by introducing Hooke's material law and given by,

$\sigma_{x}=E \varepsilon_{x}$ 
in which $E$ is the Young's modulus.

Besides the nodal forces and moments, the stresses on the cross-section along the element length, i.e. $\sigma_{x}$ and $\tau_{x y}$, can be expressed as,

$\sigma_{x}=\frac{N}{A}+\left[M_{1}\left(1-\frac{x}{L}\right)-M_{2} \frac{x}{L}\right] \frac{y}{I}+E \alpha \Delta t$

$\tau_{x y}=\frac{V}{A}=\frac{M_{1}+M_{2}}{A L}$

where, $N$ denotes the axial load; $M_{1}$ and $M_{2}$ describe the bending moments at the left and the right ends, respectively; $I$ is the moment of inertia; and, $A$ is the cross-section area.

\subsection{Formulation of total potential energy}

The total potential energy is formulated and written by,

$\Pi=U_{E}+U_{S}+U_{T}-W$

in which, $\Pi$ denotes the total potential energy; $U_{E}$ is the element strain energy; $U_{S}$ is the energy induced by surrounding soil; $U_{T}$ is the energy due to thermal expansion; and $W$ is the work conducted by the external loads.

The element strain energy is calculated by the formulation below,

$U_{E} \approx \frac{1}{2} \int_{V}\left(E\left(\varepsilon_{x}^{L}\right)^{2}+2 \sigma_{x} \varepsilon_{x}^{N}+\tau_{x y} \varepsilon_{x y}^{N}\right) d v$

$=\frac{1}{2} \int_{0}^{L} E A\left(\frac{\partial u(x)}{\partial x}\right)^{2}+E I\left(\frac{\partial^{2} v(x)}{\partial x^{2}}\right)^{2} d x+\frac{1}{2} \int_{0}^{L} P\left(\frac{\partial v(x)}{\partial x}\right)^{2} d x$

$-\int_{0}^{L} \frac{V}{A}\left(\frac{\partial u(x)}{\partial x} \frac{\partial v(x)}{\partial x}\right) d x$

The energy taken by the surrounding soils can be computed by,

$U_{S}=\int_{0}^{L} \int_{0}^{v} P(v) d v d x=\int_{0}^{L} \int_{0}^{v} \int_{0}^{v} k(v) d v d v d x=\frac{1}{2} \int_{0}^{L} k(v) v^{2} d x$

in which $P(v)$ is the soil resisting force by referring to the specified vertical deflection (Fig. 4); $v$ is the vertical deflection; $k(v)$ is the tangential value on the soil-pipeline interaction curve by referring to specified vertical deflection.

As shown in Fig. 4, the soil-pipeline interaction curve is highly nonlinear and difficult to be described by an analytical expression. Therefore, the GaussLegendre method is used in this paper to calculate the energy absorbed by the soil, and its analytical expression is as follow,

$U_{S}=\frac{1}{2} \int_{0}^{L} k(v) v^{2} d x \approx \frac{1}{2} \sum_{i=1}^{n} A_{i} k\left(v_{i}\right) v_{i}^{2}$

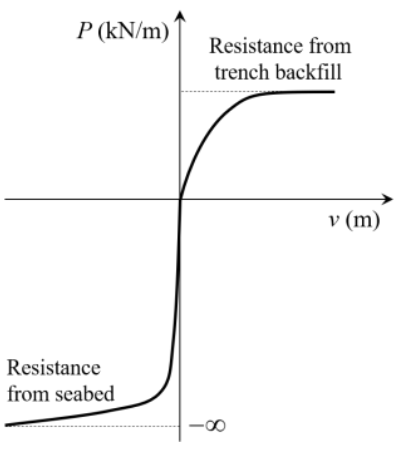

Fig. 4 Soil-pipeline interaction curve

where $A_{i}$ is the weight factors of the $i^{\text {th }}$ Gaussian point; $v_{i}$ is the vertical displacement of the $i^{\text {th }}$ Gaussian point; $n$ represents the number of Gaussian points, which is taken as 4 in this paper.

Thermal energy, also referred to as internal energy of subsea pipeline, is given by:
$U_{T}=\int_{V} E \varepsilon_{t h} \alpha \Delta t d v$

The work conducted by the external forces is given as follow,

$W=\sum_{i=1}^{6} F_{i} u_{i}$

where $u_{i}$ is the $i^{\text {th }}$ degree of freedom; and $F_{i}$ is the $i^{\text {th }}$ corresponding nodal force.

According to the minimum potential energy principal, the following equation can be obtained,

$\delta \prod=\frac{\partial \prod}{\partial u_{i}}+\frac{\partial \prod}{\partial F_{i}} \frac{\partial F_{i}}{\partial u_{i}}=0$

To eliminate the errors accumulated in the incremental-iterative numerical procedure, the secant relations, obtained by the minimum potential energy method, are used for computing element resisting forces.

\subsection{Secant relations}

The secant relations can be derived to calculate the resisting forces resulting from both subsea pipeline and its surrounding soils to predict the equilibrium conditions in the numerical procedure. The resisting forces are given by the following equations,

$\{R\}=\left\{R^{E}\right\}+\left\{R^{S}\right\}$

where

$\left\{R^{E}\right\}=\left\{\begin{array}{llllll}F_{x 1} & V_{1}^{E} & M_{1}^{E} & F_{x 2} & V_{2}^{E} & M_{2}^{E}\end{array}\right\}$

$\left\{R^{S}\right\}=\left\{\begin{array}{llllll}0 & V_{1}^{S} & M_{1}^{S} & 0 & V_{2}^{S} & M_{2}^{S}\end{array}\right\}$

in which, $F_{x 1}$ and $F_{x 2}$ are the axial resisting forces at the element ends; $M_{1}^{E}$ and $M_{2}^{E}$ denote the bending resistances from the element; $M_{1}^{S}$ and $M_{2}^{S}$ are the bending resistances resulting from the external soil pressures at the element ends; $V_{1}^{E}$ and $V_{2}^{E}$ are the shear force resistances from the elements' ends; $V_{1}^{S}$ and and $V_{2}^{S}$ are the external shear force resistances from the soils.

The element forces are calculated by the first variation of the total potential energy given as,

$F_{x 1}=\frac{E A}{L}\left(u_{1}-u_{2}\right)+\frac{\left(M_{1}^{E}+M_{2}^{E}\right)}{L^{2}}\left(-v_{1}+v_{2}\right)$

$F_{x 2}=\frac{E A}{L}\left(-u_{1}+u_{2}\right)+\frac{\left(M_{1}^{E}+M_{2}^{E}\right)}{L^{2}}\left(v_{1}-v_{2}\right)$

$M_{1}^{E}=\frac{6 E I}{L^{2}}\left(v_{1}-v_{2}\right)+\frac{2 E I}{L}\left(2 \theta_{1}+\theta_{2}\right)+\frac{N}{10}\left(v_{1}-v_{2}\right)+\frac{L N}{30}\left(4 \theta_{1}-\theta_{2}\right)$

$M_{2}^{E}=\frac{6 E I}{L^{2}}\left(v_{1}-v_{2}\right)+\frac{2 E I}{L}\left(\theta_{1}+2 \theta_{2}\right)+\frac{N}{10}\left(v_{1}-v_{2}\right)+\frac{L N}{30}\left(-\theta_{1}+4 \theta_{2}\right)$

$V_{1}^{E}=\frac{\left(M_{1}^{E}+M_{2}^{E}\right)}{L^{2}}\left(-u_{1}+u_{2}\right)+\frac{12 E I}{L^{3}}\left(v_{1}-v_{2}\right)+\frac{6 E I}{L^{2}}\left(\theta_{1}+\theta_{2}\right)$

$+\frac{6 N}{5 L}\left(v_{1}-v_{2}\right)+\frac{N}{10}\left(\theta_{1}-\theta_{2}\right)$ 
$V_{2}^{E}=\frac{\left(M_{1}^{E}+M_{2}^{E}\right)}{L^{2}}\left(u_{1}-u_{2}\right)+\frac{12 E I}{L^{3}}\left(-v_{1}+v_{2}\right)+\frac{6 E I}{L^{2}}\left(-\theta_{1}-\theta_{2}\right)$

$+\frac{6 N}{5 L}\left(-v_{1}+v_{2}\right)+\frac{N}{10}\left(-\theta_{1}-\theta_{2}\right)$

The axial force $N$ can be calculated by including the thermal expansion force as,

$N=-\frac{1}{2}\left(F_{x 1}-F_{x 2}\right)+E A \alpha \Delta t$

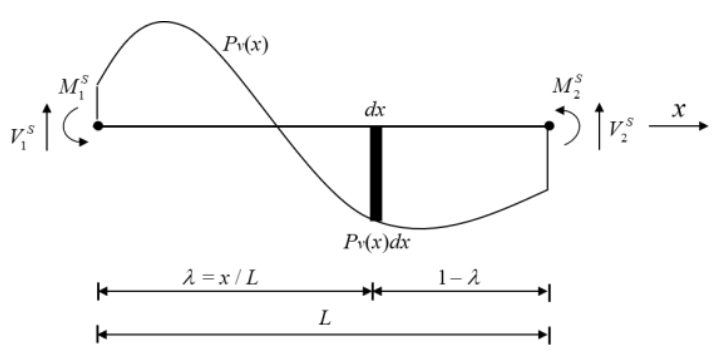

Fig. 5 Element end forces caused by surrounding soil

Fig. 5 shows the bending moments and shear forces at the end of the element induced by the surrounding soil, which can be expressed as follows,

$$
\begin{aligned}
M_{1}^{S} & =\int_{0}^{L} x\left(1-\frac{x}{L}\right)^{2} P_{v}(x) d x \\
& =\int_{0}^{1} \lambda(1-\lambda)^{2} P_{v}(\lambda L) L^{2} d \lambda \approx L^{2} \sum_{i=1}^{4} \alpha_{i} P_{v}\left(x_{i}\right)
\end{aligned}
$$

$$
\begin{aligned}
M_{2}^{S} & =-\int_{0}^{L} \frac{x^{2}}{L^{2}}(L-x) P_{v}(x) d x \\
& =-\int_{0}^{1} \lambda^{2}(1-\lambda) P_{v}(\lambda L) L^{2} d \lambda \approx-L^{2} \sum_{i=1}^{4} \beta_{i} P_{v}\left(x_{i}\right) \\
V_{1}^{S} & =\int_{0}^{L}\left(\frac{3 x}{L}+\frac{L-x}{L}\right)\left(1-\frac{x}{L}\right)^{2} P_{v}(x) d x \\
& =\int_{0}^{1}(2 \lambda+1)(1-\lambda)^{2} P_{v}(\lambda L) L d \lambda \approx L \sum_{i=1}^{4} \chi_{i} P_{v}\left(x_{i}\right)
\end{aligned}
$$

$$
\begin{aligned}
V_{2}^{S} & =-\int_{0}^{L}\left(\frac{x}{L}+\frac{3(L-x)}{L}\right)\left(\frac{x}{L}\right)^{2} P_{v}(x) d x \\
& =-\int_{0}^{1}(3-2 \lambda) \lambda^{2} P_{v}(\lambda L) L d \lambda \approx-L \sum_{i=1}^{4} \gamma_{i} P_{v}\left(x_{i}\right)
\end{aligned}
$$

where the four coefficients $\alpha_{i}, \beta_{i}, \chi_{i}$, and $\gamma_{i}$ are given in Table 1 .

\subsection{Tangent stiffness matrices}

The element stiffness matrices are formulated by the second variation of the total potential equation to predict the incremental nodal deformations, which are given by,

$\delta^{2} \Pi=\frac{\partial^{2} \prod_{i}}{\partial u_{i} \partial u_{j}} \delta u_{i} \delta u_{j}$

The element stiffness matrix $\left[k_{E}\right]$ can be re-written into four parts as,

$$
\left[k_{E}\right]=\left[k_{L}\right]+\left[k_{G}\right]+\left[k_{s}\right]+\left[k_{r_{n}}\right]
$$

where $\left[k_{L}\right]$ is the linear stiffness part; $\left[k_{G}\right]$ is the geometric stiffness part; $\left[k_{s}\right]$ is the soil stiffness matrix; and, $\left[k_{T h}\right]$ is the thermal expansion matrix.
The linear and geometric stiffness matrices can be written as,

$$
\begin{aligned}
& {\left[k_{L}\right]=\left[\begin{array}{cccccc}
\frac{E A}{L} & 0 & 0 & -\frac{E A}{L} & 0 & 0 \\
& \frac{12 E I}{L^{3}} & \frac{6 E I}{L^{2}} & 0 & -\frac{12 E I}{L^{3}} & \frac{6 E I}{L^{2}} \\
& & \frac{4 E I}{L} & 0 & -\frac{6 E I}{L^{2}} & \frac{2 E I}{L} \\
S . & & & \frac{E A}{L} & 0 & 0 \\
& Y . & & & \frac{12 E I}{L^{3}} & -\frac{6 E I}{L^{2}} \\
& & & & & \frac{4 E I}{L}
\end{array}\right]} \\
& {\left[k_{G}\right]=\left[\begin{array}{cccccc}
\frac{N}{L} & -\frac{M_{1}+M_{2}}{L^{2}} & 0 & -\frac{N}{L} & \frac{M_{1}+M_{2}}{L^{2}} & 0 \\
& \frac{6 N}{5 L} & \frac{N}{10} & \frac{M_{1}+M_{2}}{L^{2}} & -\frac{6 N}{5 L} & \frac{N}{10} \\
& & \frac{2 L N}{15} & 0 & -\frac{N}{10} & -\frac{L N}{30} \\
S . & & & \frac{N}{L} & -\frac{M_{1}+M_{2}}{L^{2}} & 0 \\
& Y . & & & \frac{6 N}{5 L} & -\frac{N}{10} \\
& M . & & & \frac{2 L N}{15}
\end{array}\right]}
\end{aligned}
$$

The soil stiffness matrix is given by,

$$
\left[k_{S}\right]=\left[\begin{array}{cccccc}
0 & 0 & 0 & 0 & 0 & 0 \\
& \sum_{i=1}^{4} \mu_{i i} k_{v i} L & \sum_{i=1}^{4} \mu_{2 i} k_{v i} L^{2} & 0 & \sum_{i=1}^{4} \mu_{3 i} k_{v i} L & \sum_{i=1}^{4} \mu_{4 i} k_{v i} L^{2} \\
& & \sum_{i=1}^{4} \mu_{5 i} k_{v i} L^{3} & 0 & \sum_{i=1}^{4} \mu_{6 i} k_{v i} L^{2} & \sum_{i=1}^{4} \mu_{7 i} k_{v i} L^{3} \\
S . & & & 0 & 0 & 0 \\
& Y . & & & \sum_{i=1}^{4} \mu_{8 i} k_{v i} L & \sum_{i=1}^{4} \mu_{9 i} k_{v i} L^{2} \\
& & & & & \sum_{i=1}^{4} \mu_{10 i} k_{v i} L^{3}
\end{array}\right]
$$

where the coefficients $\mu_{1 i}$ to $\mu_{10 i}$ are given in Table 2 .

The thermal matrix can be written as,

$$
\left[k_{T h}\right]=\left[\begin{array}{cccccc}
\frac{E A \alpha \Delta t}{L} & 0 & 0 & -\frac{E A \alpha \Delta t}{L} & 0 & 0 \\
& \frac{6 E A \alpha \Delta t}{5 L} & \frac{E A \alpha \Delta t}{10} & 0 & -\frac{6 E A \alpha \Delta t}{5 L} & \frac{E A \alpha \Delta t}{10} \\
& & \frac{2 E A L \alpha \Delta t}{15} & 0 & -\frac{E A \alpha \Delta t}{10} & -\frac{E A L \alpha \Delta t}{30} \\
S . & & & 0 & 0 & 0 \\
& Y . & & & \frac{6 E A \alpha \Delta t}{5 L} & -\frac{E A \alpha \Delta t}{10} \\
& & M . & & & \frac{2 E A L \alpha \Delta t}{15}
\end{array}\right]
$$

\section{Updated-lagrangian method}

\subsection{Transformation matrices}

Since the subsea buried pipelines could exhibit large deformations under the ultimate limit state, especially for simulating the upheaval buckling, the 
equilibrium condition through the Updated Lagrangian (UL) description is established and illustrated in Fig. 6.

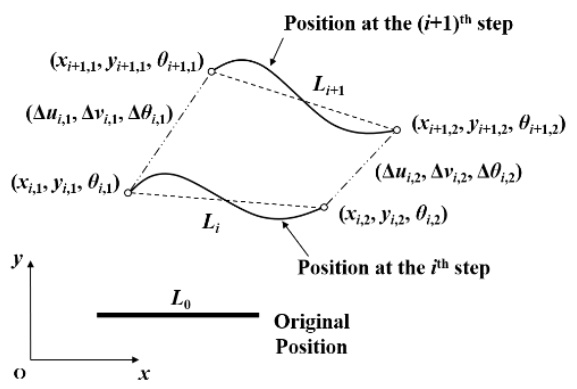

Fig. 6 Updated-Lagrangian (UL) method for large deflections

Table 1

Coefficients $\alpha_{i}, \beta_{i}, \chi_{i}$, and $\gamma_{i}$ in the secant relations

\begin{tabular}{ccccc}
\hline & \multicolumn{4}{c}{ Gaussian point ID } \\
\cline { 2 - 5 } Location $x / L$ & 1 & 2 & 3 & 4 \\
\cline { 2 - 5 } & 0.06943 & 0.33001 & 0.66999 & 0.93057 \\
\hline$\alpha$ & 0.01046 & 0.04830 & 0.02379 & 0.00078 \\
$\beta$ & 0.00078 & 0.02379 & 0.04830 & 0.01046 \\
$\chi$ & 0.17153 & 0.24298 & 0.08310 & 0.00240 \\
$\gamma$ & 0.00240 & 0.08310 & 0.24298 & 0.17153 \\
\hline
\end{tabular}

Table 2

Coefficients $\mu_{1 i}$ to $\mu_{10 i}$ in the soil stiffness [ks]

\begin{tabular}{ccccc}
\hline & \multicolumn{4}{c}{ Gaussian point ID } \\
\cline { 2 - 5 } Location $x / L$ & 1 & 2 & 3 & 4 \\
\cline { 2 - 5 } & 0.06943 & 0.33001 & 0.66999 & 0.93057 \\
\hline$\mu_{1}$ & 0.16916 & 0.18106 & 0.02118 & 0.00003 \\
$\mu_{2}$ & 0.01031 & 0.03599 & 0.00606 & 0.00001 \\
$\mu_{3}$ & 0.00237 & 0.06192 & 0.06192 & 0.00237 \\
$\mu_{4}$ & -0.00077 & -0.01773 & -0.01231 & -0.00014 \\
$\mu_{5}$ & 0.00063 & 0.00716 & 0.00174 & 0.00000 \\
$\mu_{6}$ & 0.00014 & 0.01231 & 0.01773 & 0.00077 \\
$\mu_{7}$ & -0.00005 & -0.00352 & -0.00352 & -0.00005 \\
$\mu_{8}$ & 0.00003 & 0.02118 & 0.18106 & 0.16916 \\
$\mu_{9}$ & -0.00001 & -0.00606 & -0.03599 & -0.01031 \\
$\mu_{10}$ & 0.00000 & 0.00174 & 0.00716 & 0.00063 \\
\hline
\end{tabular}

The Updated-Lagrangian (UL) method is achieved by updating the transformation relations between the local and global coordinate system with the latest configuration. The transformation matrix $[L]_{i}$ is written as,

$$
[L]_{i}=[L]_{i-1}[\Delta L]_{i}
$$

The transformation matrix $[L]_{0}$ is determined by,

$$
[L]_{0}=\left[\begin{array}{ll}
{\left[L^{\prime}\right]_{0}} & \\
& {\left[L^{\prime}\right]_{0}}
\end{array}\right]
$$

in which

$$
\left[L^{\prime}\right]_{0}=\left[\begin{array}{ccc}
\frac{x_{0,2}-x_{0,1}}{L_{0}} & -\frac{y_{0,2}-y_{0,1}}{L_{0}} & 0 \\
\frac{y_{0,2}-y_{0,1}}{L_{0}} & \frac{x_{0,2}-x_{0,1}}{L_{0}} & 0 \\
0 & 0 & 1
\end{array}\right]
$$

$L_{0}=\sqrt{\left(x_{0,2}-x_{0,1}\right)^{2}+\left(y_{0,2}-y_{0,1}\right)^{2}}$

where the first subscript 0 denotes the original position; and, the second subscripts 1 and 2 represent the element nodes.

The updated transformation matrix $\Delta[L]_{i}$ is updated by,

$[\Delta L]_{i}=\left[\begin{array}{ll}{\left[\Delta L^{\prime}\right]_{i}} & \\ & {\left[\Delta L^{\prime}\right]_{i}}\end{array}\right]$

where

$$
\begin{aligned}
& {\left[\Delta L^{\prime}\right]_{i}=\left[\begin{array}{ccc}
\sqrt{1-\left(\frac{\Delta v_{i, 2}-\Delta v_{i, 1}}{L_{i}}\right)^{2}} & -\frac{\Delta v_{i, 2}-\Delta v_{i, 1}}{L_{i}} & 0 \\
\frac{\Delta v_{i, 2}-\Delta v_{i, 1}}{L_{i}} & \sqrt{1-\left(\frac{\Delta v_{i, 2}-\Delta v_{i, 1}}{L_{i}}\right)^{2}} & 0 \\
0 & 1 \\
0 & \\
L_{i}=\sqrt{\left(L_{i-1}+\Delta u_{i, 2}-\Delta u_{i, 1}\right)^{2}+\left(\Delta v_{i, 2}-\Delta v_{i, 1}\right)^{2}}
\end{array}\right]}
\end{aligned}
$$

in which $\Delta u_{i, 1}$ and $\Delta u_{i, 2}$ are the incremental nodal axial deformation; and, $\Delta v_{i, 1}$ and $\Delta v_{i, 2}$ are the incremental nodal vertical displacements.

\subsection{Formulation of the global tangent stiffness matrix}

After obtaining the element stiffness matrix, the global stiffness matrix is assembled by summing up the element stiffness matrix given as,

$$
[K]=\sum_{i=1}^{N E L E}\left([L]_{i}\left(\left[k_{L}\right]+\left[k_{G}\right]+\left[k_{S}\right]+\left[k_{T h}\right]\right)[L]_{i}^{T}\right)
$$

where $[K]$ denote the global tangent stiffness matrix; while $N E L E$ is the element number.

\subsection{Newton-Raphson typed numerical procedure}

A Newton-Raphson method, using the incremental-iterative solution procedure, is adopted by updating the tangent stiffness matrix during the iteration. The incremental nodal displacements can be calculated as,

$$
\{\Delta U\}=\{\Delta F\}[K]^{-1}
$$

in which, $\{\Delta U\}$ denote the incremental nodal displacements; while $\{\Delta F\}$ represents the unbalanced forces.

The element nodal displacement can be calculated by,

$\{\Delta u\}=[L]_{i}\{\Delta U\}$

in which, $\{\Delta u\}$ is the element nodal displacement vector.

The resisting forces in this analysis at each load-increment can be obtained at the $i^{t h}$ position according to the last-known status at the $(i-1)^{\text {th }}$ position. The global resisting force can be summed up by,

$\{R\}_{i}=\{R\}_{i-1}+\sum_{i=1}^{N E L E}[L]_{i}^{T}\{\Delta r\}$

where $\{R\}_{i-1}$ denote the global resisting force vector at the $(i-1)^{t h}$ step; while, $\{\Delta r\}$ describes the element resisting force vector.

An incremental-iterative analysis procedure, via the Newton-Raphson typed numerical method, is developed, which is schematically presented in Fig. 7. The Newton-Raphson procedure is to divide the nonlinear problem into a 
series of linear solutions. One or more times of iterations are required at each load increment to minimize the numerical errors, which can be measured by the norm of the unbalanced force vector $\Delta F$,

$$
\{\Delta F\}=\{F\}_{i}-\{R\}_{i}
$$

The expression of convergence criterion with respect to the residual forces and displacements are introduced,

$$
\{\Delta U\}^{T}\{\Delta U\} \leq T O L \times\{U\}^{T}\{U\}
$$

$$
\{\Delta F\}^{T}\{\Delta F\} \leq T O L \times\{R\}^{T}\{R\}
$$

in which $T O L$ is the convergence tolerance.

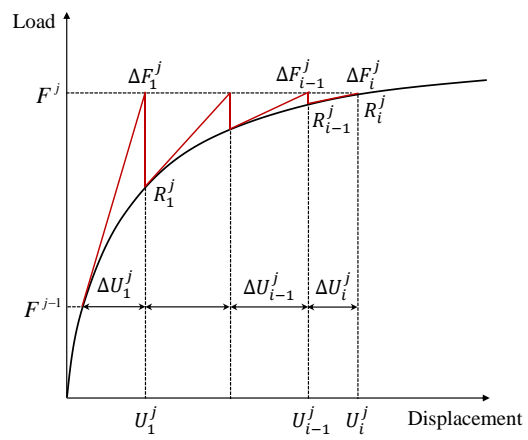

Fig. 7 Newton-Raphson typed numerical procedure

\section{Numerical analysis procedure}

The numerical analysis procedure is proposed to determine the critical temperature to trigger the upheaval buckling of pipelines, illustrated in Fig. 8. As can be seen from the flowchart, the analysis procedure contains two steps. The first analysis step is to determine initial deformation and stress within the pipeline, while the second step is to apply the cumulative temperature to the pipeline until triggering the buckling.

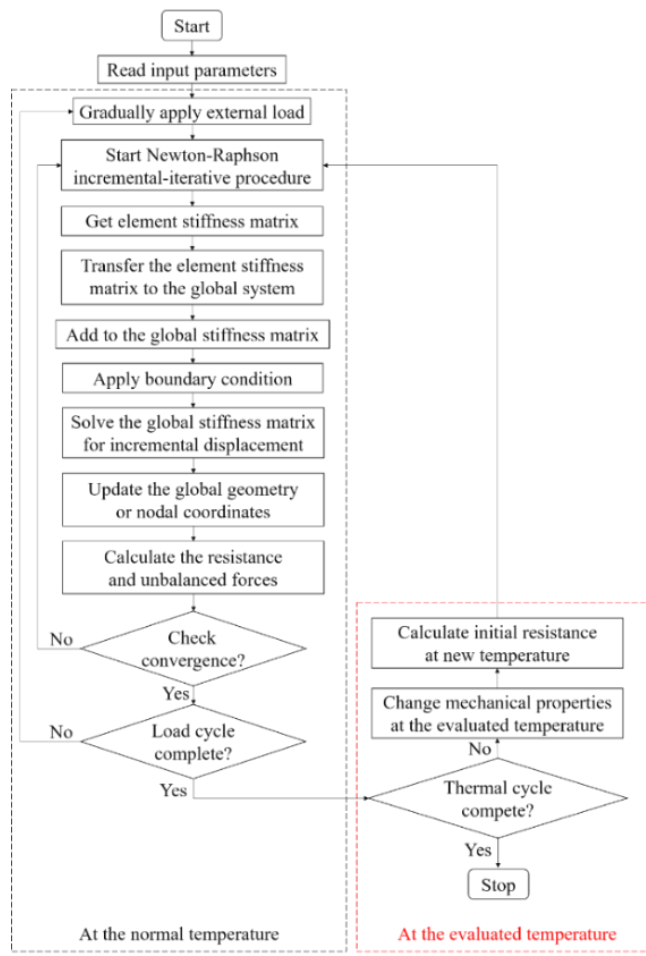

Fig. 8 An incremental-iterative analysis procedure

\section{Verification examples}

Three groups of examples are provided for examining the analysis accuracy and numerical robustness of the proposed numerical algorithms in capturing buckling behaviors of pipelines due to thermal expansion

6.1. Example 1-Upheaval buckling of pipelines in soft soil due to thermal expansion

In this example, the upheaval buckling behaviors of a series of pipelines in soft soil (see Fig. 9) due to thermal expansion are computed by the analytical solutions. The results will be used as benchmarks for validating the proposed numerical algorithms. The analytical solution derived by $\mathrm{Li}$ et al. [36] to compute the buckling strength of a buried pipeline under thermal expansion can be written as,

$$
P_{c r}=E A \alpha \Delta t_{c r}=\frac{\pi^{2} E I}{L_{c r}{ }^{2}}+k_{s p} \frac{L_{c r}{ }^{2}}{\pi^{2}}
$$

where, $\Delta t_{c r}$ is the critical temperature to trigger the upheaval buckling; $\alpha$ is the thermal expansion coefficient; $E$ is the Young's modulus; $A$ is the section area; $I$ is the moment of inertia; $k_{s p}$ is the stiffness of soil springs; and $L_{c r}$ is the critical buckling length.

This equation can be rewritten as follow for determining the critical temperature onset of triggering the upheaval buckling,

$\Delta t_{c r}=\left(\frac{\pi^{2} E I}{L_{c r}{ }^{2}}+k_{s p} \frac{L_{c r}{ }^{2}}{\pi^{2}}\right) \frac{1}{\alpha E A}$

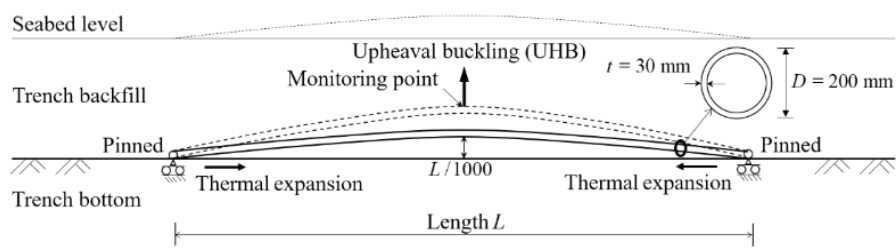

Fig. 9 Upheaval buckling of a buried pipe with both ends pinned

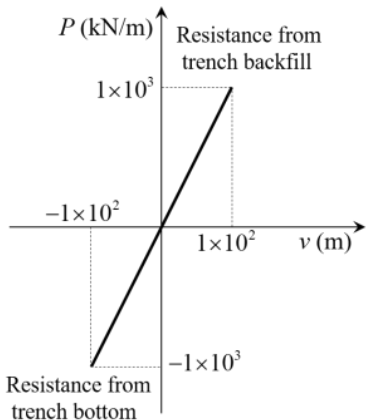

Fig. 10 Soil-pipeline interaction curve of a buried pipe with both ends pinned

Six pipelines are studied for investigating their upheaval buckling behaviors under thermal expansion, and they are all using the circular hollow section with the diameter and the wall thickness as $200 \mathrm{~mm}$ and $30 \mathrm{~mm}$, respectively. The material is steel, and the Young's modulus, the Possion's ratio and the thermal expansion coefficients are $205 \mathrm{GPa}, 0.3$ and $1.2 \times 10^{-5} \mathrm{~m} / \mathrm{m} \cdot{ }^{\circ} \mathrm{C}$, respectively. The lengths of the pipelines are varied with different values, given as $6 \mathrm{~m}$, $7 \mathrm{~m}, 8 \mathrm{~m}, 10 \mathrm{~m}, 15 \mathrm{~m}$ and $20 \mathrm{~m}$. The pipelines are embedded in trench backfill with the soil stiffness as $10 \mathrm{kN} / \mathrm{m}^{2}$. The soil-pipeline interaction curve in this example is shown in Fig. 10.

The buckling length is critical for assessing the buckling of pipelines. For simplicity, these pipelines are pinned at both ends (as shown in Fig. 9), and the buckling lengths are their member lengths. The buckling analyses for these pipelines are performed by the proposed numerical method, where two cases of using 2 and 4 elements to model a pipeline are studied. It is observed from Table 3 that, the proposed method is with high analysis accuracy and the error of using 4 elements to model a long pipeline is less than $0.08 \%$. The nonlinear buckling analysis is conducted for these pipelines, and the load versus deflection curves 
are plotted in Fig. 11. The present study confirms the analysis accuracy of the proposed method in determining the critical load of triggering the upheaval buckling of a pipeline.

Table 3

Critical temperatures to trigger buckling of the pipelines

\begin{tabular}{cccccc}
\hline \multirow{2}{*}{ Length $(\mathrm{m})$} & Theoretical & \multicolumn{5}{c}{ Present Study } \\
\cline { 2 - 6 } & Solution & 2 Elements & Difference & 4 Elements & Difference \\
\cline { 2 - 6 } & $\Delta t c r\left({ }^{\circ} \mathrm{C}\right)$ & $\Delta t c r\left({ }^{\circ} \mathrm{C}\right)$ & $(\%)$ & $\Delta \operatorname{tcr}\left({ }^{\circ} \mathrm{C}\right)$ & $(\%)$ \\
\hline 6 & 86.03 & 86.69 & 0.773 & 86.10 & 0.080 \\
7 & 63.78 & 64.27 & 0.766 & 63.83 & 0.079 \\
8 & 49.52 & 49.89 & 0.755 & 49.55 & 0.078 \\
10 & 33.21 & 33.45 & 0.718 & 33.23 & 0.074 \\
15 & 19.40 & 19.50 & 0.537 & 19.41 & 0.033 \\
20 & 17.94 & 17.99 & 0.296 & 17.95 & 0.020 \\
\hline Mean $(\%)$ & & & 0.641 & & 0.061 \\
SD $(\%)$ & & & 0.427 & & 0.060 \\
\hline
\end{tabular}

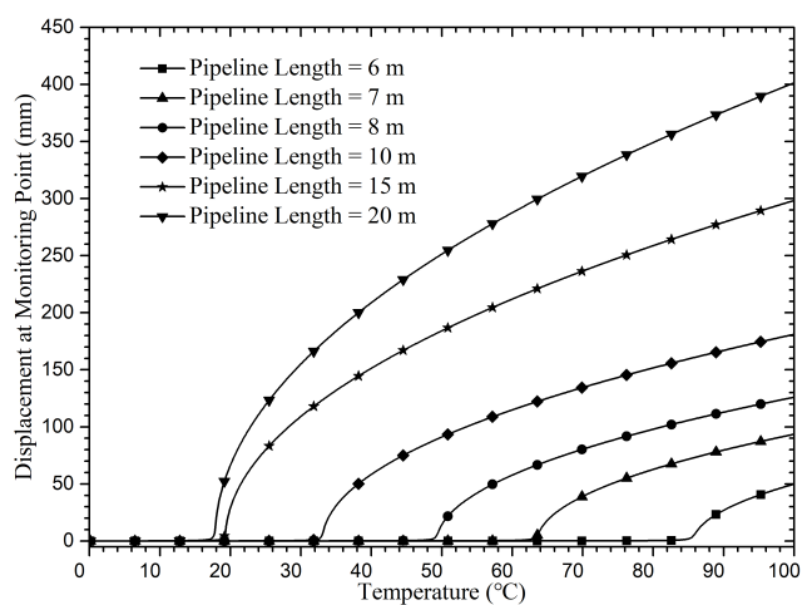

Fig. 11 Buckling behaviors of the pipelines due to thermal expansions

\subsection{Example 2-Thermal upheaval buckling of long buried sea pipelines}

This example investigates the upheaval buckling behavior of buried pipelines with different out-of-straightness and different initial imperfection shapes. The analysis problem is illustrated in Fig. 12.

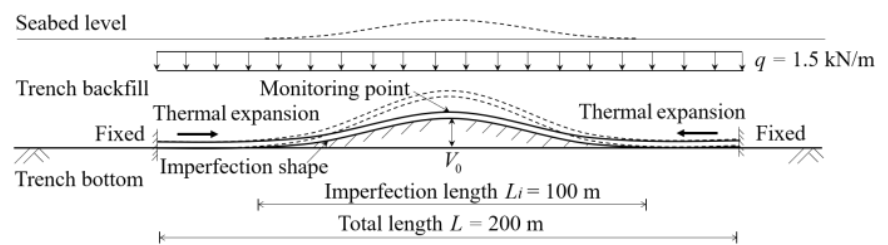

Fig. 12 Pipeline model resting on the semi-rigid seabed

The pipelines are made by steel and the Young's modulus, the Poisson's ratio, and the thermal coefficient are $207 \mathrm{GPa}, 0.3$, and $1.17 \times 10^{-5} \mathrm{~m} / \mathrm{m} \cdot{ }^{\circ} \mathrm{C}$, respectively. Six pipelines are studied for investigating their upheaval buckling behaviors under thermal expansion, and they are all using the circular hollow section with the diameter and the wall thickness as $457 \mathrm{~mm}$ and $14.3 \mathrm{~mm}$, respectively. The total length of these pipelines is $200 \mathrm{~m}$, and the initial imperfection length is $100 \mathrm{~m}$. In the proposed pipeline element method, one element per 2 meters is used to simulate the pipeline, and the two ends of the pipeline are fixed.

Assuming that the pipeline is placed on a semi-rigid seabed and the sum of the trench backfill and the pipeline's self-weight is $1.5 \mathrm{kN} / \mathrm{m}$, the soil-pipeline interaction curve is shown in Fig. 13. So if the downward displacement of the pipeline is $1 \times 10^{-5} \mathrm{~m}$, the resistance of the seabed is $2000 \mathrm{kN} / \mathrm{m}$, which is a relative large value that can satisfy the rigid seabed assumption.

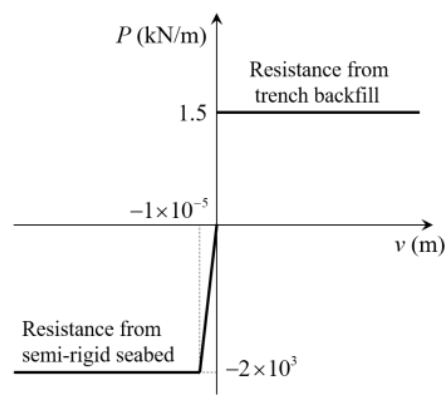

Fig. 13 Soil-pipeline interaction curve of buried pipeline with both ends fixed

Two out-of-straightness are employed in this example, such as 1/100 and $1 / 200$, to investigate the pipelines' upheaval buckling behavior. For each value of out-of-straightness, the pipeline has three initial imperfection shapes, which the following equations can determine:

Imperfection Shape Type 1,

$V_{i}^{1}(x)=\left\{\begin{array}{l}V_{0}\left(\frac{8}{3}\left(\frac{2 x}{L_{i}}\right)^{2}+3 \frac{2 x}{L_{i}}+1\right)\left(1-\frac{2 x}{L_{i}}\right)^{3}, 0 \leq x \leq \frac{L_{i}}{2} \\ V_{0}\left(\frac{8}{3}\left(\frac{2 x}{L_{i}}\right)^{2}-3 \frac{2 x}{L_{i}}+1\right)\left(1+\frac{2 x}{L_{i}}\right)^{3},-\frac{L_{i}}{2} \leq x \leq 0\end{array}\right.$

Imperfection Shape Type 2,

$V_{i}^{2}(x)=\frac{V_{0}}{2}\left(1+\cos \left(\frac{2 \pi x}{L_{i}}\right)\right),-\frac{L_{i}}{2} \leq x \leq \frac{L_{i}}{2}$

Imperfection Shape Type 3,

$V_{i}^{3}(x)=\left\{\begin{array}{l}V_{0}\left(4 \frac{2 x}{L_{i}}+1\right)\left(\frac{2 x}{L_{i}}-1\right)^{4}, 0 \leq x \leq \frac{L_{i}}{2} \\ -V_{0}\left(4 \frac{2 x}{L_{i}}-1\right)\left(\frac{2 x}{L_{i}}+1\right)^{4},-\frac{L_{i}}{2} \leq x \leq 0\end{array}\right.$

The whole analysis process is divided into two steps. In the first step, the unit submerged weight is applied, and then the temperature is gradually increased to the target temperature, which is set to $100^{\circ} \mathrm{C}$ in this example.

This example's analytical results will be compared with those of Zeng et al. [37] using the commercial finite element software ABAQUS. The FEA model of Zeng et al. simulates the pipeline using the Timoshenko beam element (PIPE21) and the rigid element (R2D2) to simulate the rigid seabed and the contact between the pipeline and the seabed was simulated by surface-to-surface contact. The comparison results of temperature-displacement curves at the monitoring point are shown in Fig. 14 and Fig. 15. The results show that the proposed pipeline element method using one element per two meters can accurately capture the pipeline's upheaval buckling behavior.

\subsection{Example 3-Thermal upheaval buckling of unburied sea pipelines with free span}

Due to the complex seabed conditions, pipelines' free span is inevitable, which may result in upheaval buckling failure of a pipeline under service conditions. In this example, a submarine pipeline with a $32 \mathrm{~m}$ long free span is selected to study the deformation of the whole process of pipeline heating. The analytical model is shown in Fig. 16.

The pipeline material is steel with Young's modulus of $207 \mathrm{GPa}$, Poisson's ratio of 0.3 , and a thermal expansion coefficient of $1.1 \times 10^{-5} \mathrm{~m} / \mathrm{m} \cdot{ }^{\circ} \mathrm{C}$. The tube diameter is $381 \mathrm{~mm}$, and the thickness is $12 \mathrm{~mm}$. The length of the free span is $32 \mathrm{~m}$, and the total length of the pipeline is 50 times the length of the free span. One element per 2 meters is used to model the pipeline in the proposed pipeline element method. Since the pipeline is not buried by the backfill in this example, it is assumed that the pipeline is pinned at both ends. Except for the free span, the rest of the pipeline is placed on the semi-rigid seabed, and the soil-pipeline interaction curve is shown in Fig. 17. The unit self-weight of the pipeline is $1.0 \mathrm{kN} / \mathrm{m}$.

The whole analysis process is divided into two steps. Firstly, the self-weight 
of the pipeline is applied to produce the initial deformation. Then, the temperature is gradually increased to the target temperature of $100^{\circ} \mathrm{C}$.

This example's analytical results will be compared with those of Chen et al. [38] using the commercial finite element software ABAQUS. Chen et al. simulate the pipeline with a beam element (B21), and the rigid contact surface (R2D2) simulates the rigid seabed. The temperature versus displacement of the pipeline for the whole heating process is shown in Fig. 18. Since the pipeline deformation far from the free span is minimal, only $200 \mathrm{~m}$ lengths in the middle span are taken to show the results. It can be seen from Fig. 18 that the overall results are in good agreement with those of Chen et al. However, the position of the free span part of the pipeline obtained by the proposed method is slightly below than that observed from Chen et al. This is probably because Chen et al. used the fully restrained boundary condition in the numerical simulation, while the seabed condition modeled in the proposed method is semi-rigid. In general, the results obtained from the proposed pipeline element method show in good agreement with that of using discrete spring element model, which verifies the accuracy of the proposed method.

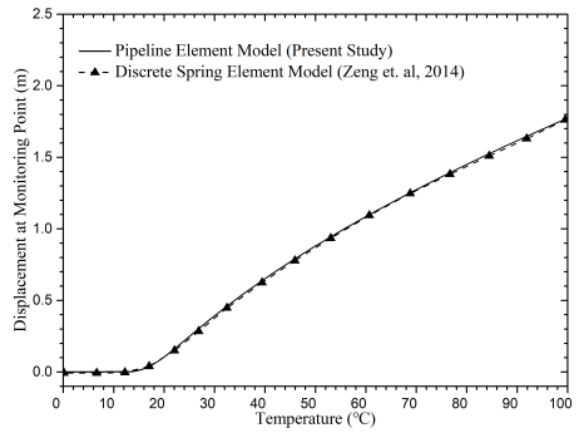

(a) Imperfection Shape Type 1

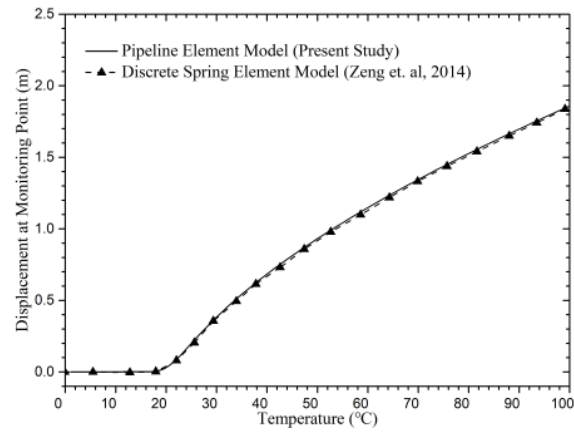

(b) Imperfection Shape Type 2

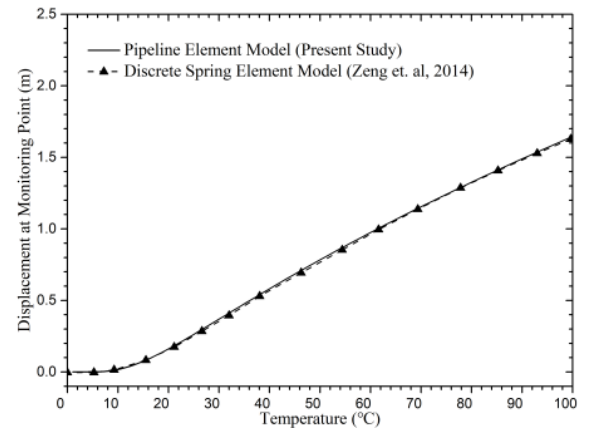

(c) Imperfection Shape Type 3

Fig. 14 Out-of-straightness equal to $1 / 100$

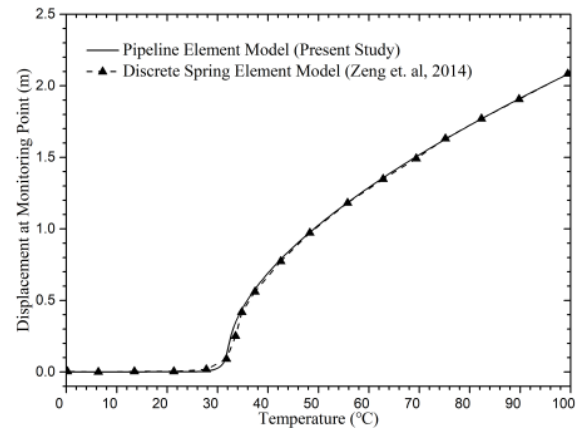

(a) Imperfection Shape Type 1

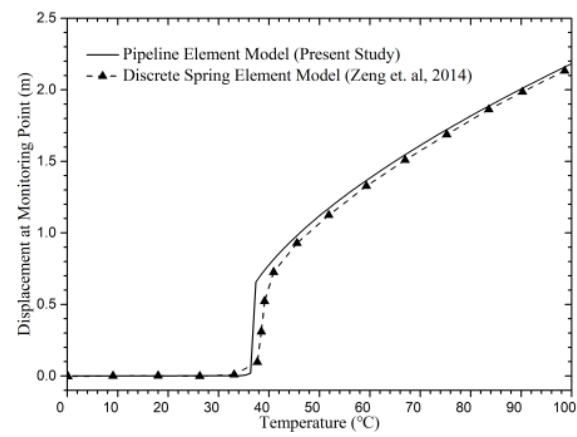

(b) Imperfection Shape Type 2

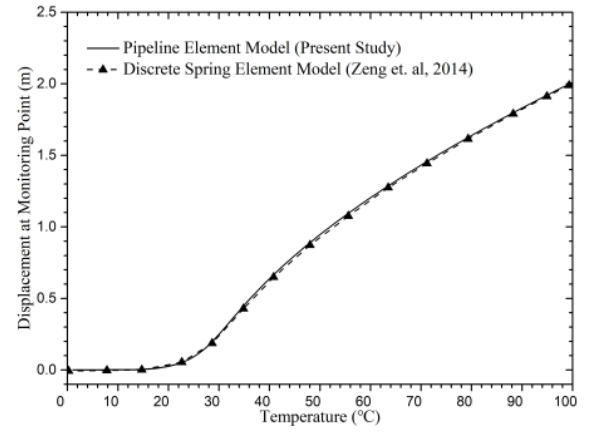

(c) Imperfection Shape Type 3

Fig. 15 Out-of-straightness equal to $1 / 200$

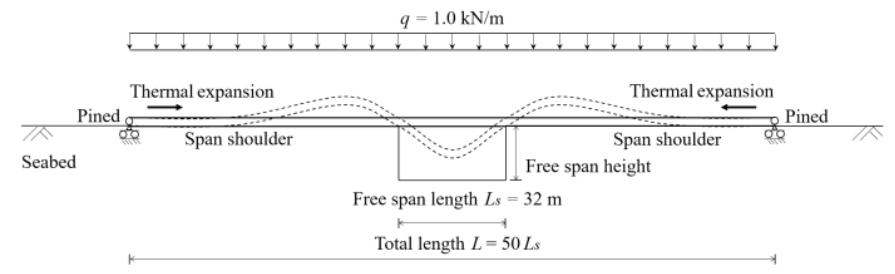

Fig. 16 Pipeline model with free span

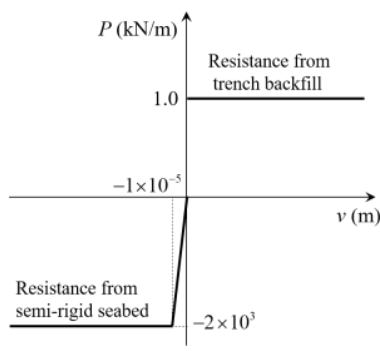

Fig. 17 Soil-pipeline interaction curve of pipeline with free span

\section{Case studies}

In this section, a case study investigating the influential factors related to the upheaval buckling of the pipeline due to thermal expansion is expected. Four variables are defined, i.e., the unit submerged weight, the tube diameter, the imperfection length, and the imperfection amplitude. Accordingly, eleven pipelines are modeled to reflect the variations of these four influential factors, whose analysis properties are tabulated in Table 4 .

Table 4

The variables in the parametric study for thermal upheaval buckling

\begin{tabular}{|c|c|c|c|c|c|}
\hline Pipeline & \multirow[t]{2}{*}{ Variables } & $\begin{array}{c}\text { Unit submerged } \\
\text { weight }\end{array}$ & Diameter & $\begin{array}{c}\text { Imperfection } \\
\text { length }\end{array}$ & $\begin{array}{c}\text { Imperfection } \\
\text { amplitude }\end{array}$ \\
\hline No. & & $q(\mathrm{kN} / \mathrm{m})$ & $D(\mathrm{~mm})$ & $L_{i}(\mathrm{~m})$ & $V_{0}(\mathrm{~m})$ \\
\hline PL-1 & Unit & 1.5 & 273 & 20 & 0.1 \\
\hline PL-2 & submerged & 2.0 & 273 & 20 & 0.1 \\
\hline PL-3 & weight & 2.5 & 273 & 20 & 0.1 \\
\hline PL-4 & & 1.5 & 323 & 20 & 0.1 \\
\hline PL-5 & Diameter & 1.5 & 355 & 20 & 0.1 \\
\hline PL-6 & & 1.5 & 381 & 20 & 0.1 \\
\hline PL-7 & Imperfection & 1.5 & 381 & 40 & 0.3 \\
\hline PL-8 & length & 1.5 & 381 & 60 & 0.3 \\
\hline PL-9 & & 1.5 & 381 & 70 & 0.3 \\
\hline PL-10 & Imperfection & 1.5 & 381 & 70 & 0.4 \\
\hline PL-11 & amplitude & 1.5 & 381 & 70 & 0.6 \\
\hline
\end{tabular}


These pipelines are $160 \mathrm{~m}$ long with both fixed end conditions and made by steel tubes with the Young's modulus, the Poisson's ratio and the thermal expansion coefficient are $207 \mathrm{GPa}, 0.3$ and $1.17 \times 10^{-5} \mathrm{~m} / \mathrm{m} \cdot{ }^{\circ} \mathrm{C}$, respectively. These pipelines are all using a circular hollow section with a wall thickness of $12 \mathrm{~mm}$. They are located on the semi-rigid foundation and modeled by the proposed pipeline elements, where the element length is 2 meters. There is an initial imperfection amplitude $V_{i}(x)$ in the middle region of the pipeline model, which

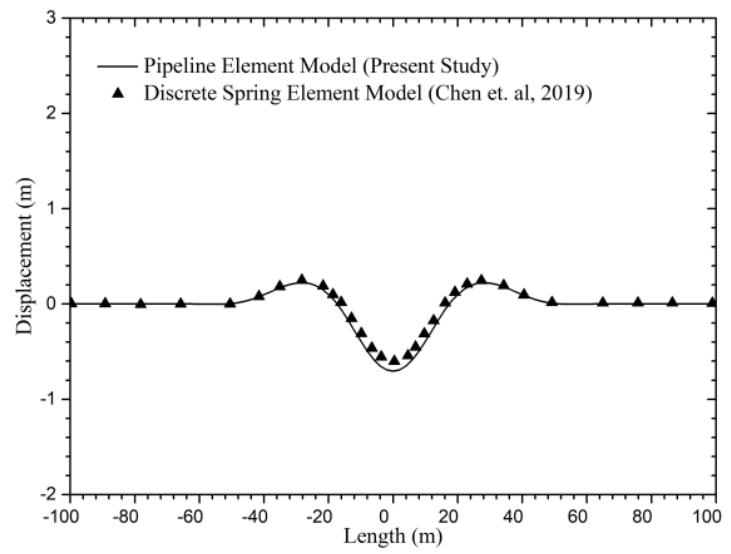

(a) Temperature difference $=29.01^{\circ} \mathrm{C}$

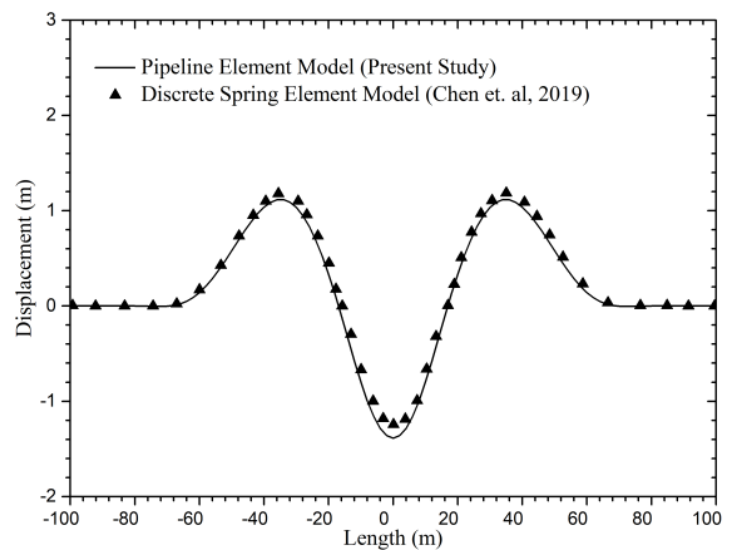

(c) Temperature difference $=64.04^{\circ} \mathrm{C}$ can be defined as the following equation,

$V_{i}(x)=V_{0}\left(\cos \left(2 \pi x / L_{i}\right)+1\right) / 2$

where $V_{0}$ is the maximum amplitude of imperfection; $L_{i}$ is the imperfection length; $x$ is the distance from the middle point of the pipeline model (Fig. 19).

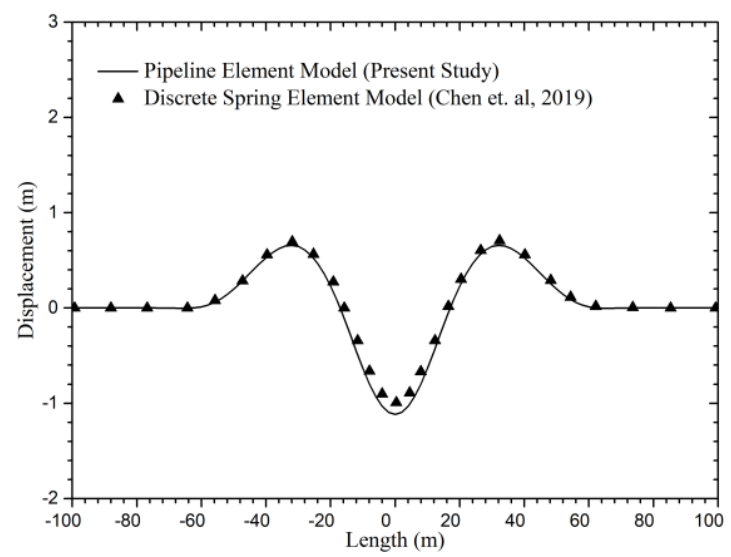

(b) Temperature difference $=42.71^{\circ} \mathrm{C}$

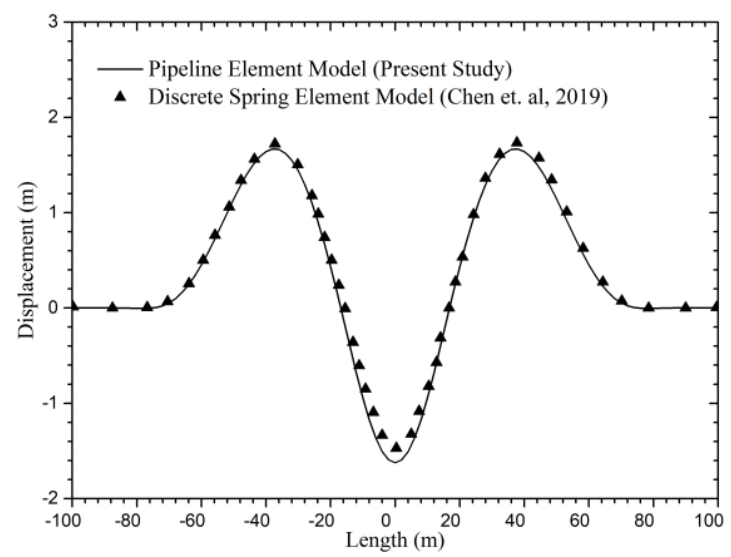

(d) Temperature difference $=94.04^{\circ} \mathrm{C}$

Fig. 18 Displacement of pipeline under different temperature

Seabed level
Trench backfill
Fixed
Trench bottom
Thermal expansion

Fig. 19 Pipeline model with initial imperfection

Each pipeline segment is loaded by downward line force $q$ to model the unit submerged weight. Meanwhile, each pipeline segment is loaded by thermal expansion till the temperature difference reaches up to $100^{\circ} \mathrm{C}$, and the temperature versus displacement curve of the middle point of each pipeline is obtained.

The parametric study results for these eleven pipelines are plotted in Fig. 20, from where the following observations are given:

(1) As shown in Fig. 20 (a), the critical temperature affects by the unit submerged weight, while the increment of the unit submerged weight will increase the critical temperature dramatically. Before the temperature reaches the critical temperature, the vertical displacement at the pipelines' middle point changes very little as the temperature increases. However, when the temperature reaches the critical temperature, the vertical displacement at the pipelines' middle point increases rapidly until a new equilibrium condition is reached. Then, as the temperature rises, the displacement at the pipelines' middle point increases slowly again. After the pipeline's buckling occurs, the larger the unit submerged weight is at the same temperature, the smaller the pipeline's vertical displacement.
(2) It can be seen from Fig. 20 (b) that the increment of tube diameter can effectively raise the critical temperature of the upheaval buckling of pipelines. Unlike the influence of unit submerged weight on pipe upheaval buckling, after the pipeline's buckling occurs, the larger the tube diameter, the larger the displacement at the pipeline's middle point at the same temperature.

(3) For a given initial imperfection amplitude $\left(V_{0}=0.3 \mathrm{~m}\right)$ of pipeline, as shown in Fig. 20 (c), when the imperfection length is small $(\mathrm{Li}=40 \mathrm{~m})$ the vertical displacement at the middle point of the pipeline is slowly developed with the temperature increase. When the imperfection length is longer $(\mathrm{Li}=70 \mathrm{~m})$, there is a critical temperature at which the displacement in the pipeline's middle span increases sharply.

(4) As illustrated in Fig. 20 (d), for a given initial imperfection length ( $L$ $=70 \mathrm{~m})$ when the imperfection amplitude is small $\left(V_{0}=0.3 \mathrm{~m}\right)$, a critical temperature will appear during the process of heating the pipeline, and the vertical displacement at the middle point of the pipeline will increase sharply at this temperature. When the imperfection amplitude is larger $\left(V_{0}=0.6 \mathrm{~m}\right)$, the pipeline's vertical displacement will not increase sharply but will increase slowly with temperature.

\section{Conclusion}

In this paper, considering the nonlinear soil-structure interaction responses, a newline element, namely pipeline element, is proposed for efficient analysis of the upheaval buckling for pipelines due to thermal expansion. The buried soils are modeled by the springs distributed continuously along with the element and are directly integrated into the element formulations. The element tangent stiffness matrix and secant relations are formulated with the details provided. Another distinct feature is the direct simulation of thermal expansion acting to 
the pipeline via the thermal stiffness matrix, whose derivation is elaborated. Three groups of examples are given to examine the proposed method. Finally, a case study is given to identify the influential factors to the upheaval buckling. The conclusions drawn from this paper are summarized as following:

- A new line element, named pipeline element, is developed and verified by three groups of examples. A case study is given to investigate the influence of several factors such as the unit submerged weight, the tube diameter, the imperfection length, and the imperfection amplitude.

- The unit submerged weight influences the critical temperature dramatically, and an increase in the unit submerged weight increases the critical temperature.

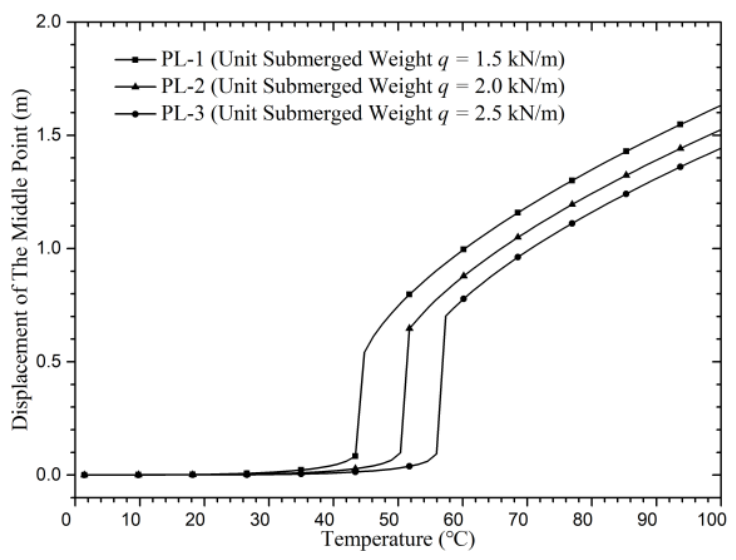

(a) Influenced by the unit submerged weight

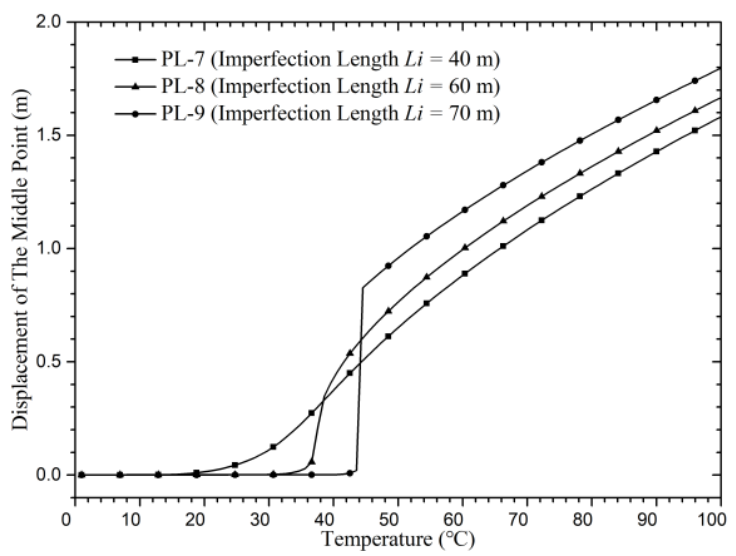

(c) Influenced by the imperfection length
- As the tube diameter increases, the pipeline's critical temperature will increase, and the critical displacement will become larger.

- The out-of-straightness and imperfection shape of the pipeline have a big influence on the upheaval buckling behavior. When the out-of-straightness is small, or the imperfection shape is not compacted, the jump buckling will occur. When the out-of-straightness is large or the imperfection shape is compacted, there is no critical temperature but the first lift-off temperature.

This research improves the numerical efficiency for analyzing the pipeline's upheaval buckling due to thermal expansion significantly. With the availability of this method, the stability design of the subsea buried pipelines for preventing the upheaval buckling, due to thermal expansion, could be more reliable and effective.

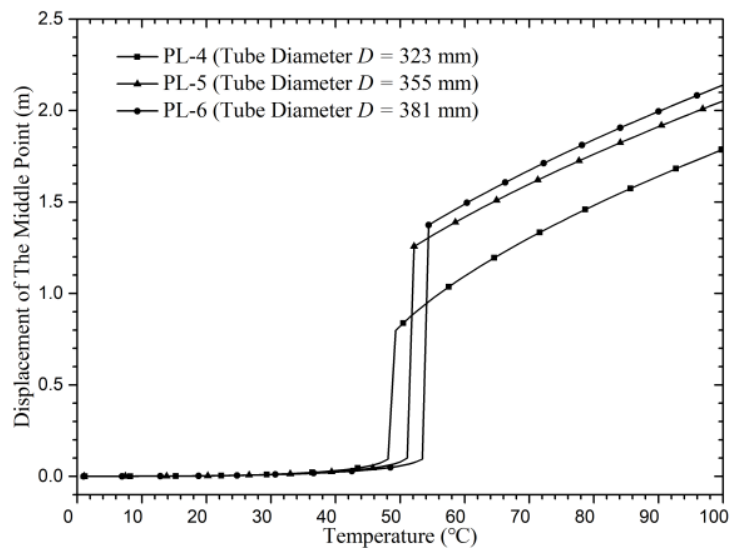

(b) Influenced by the tube diameter

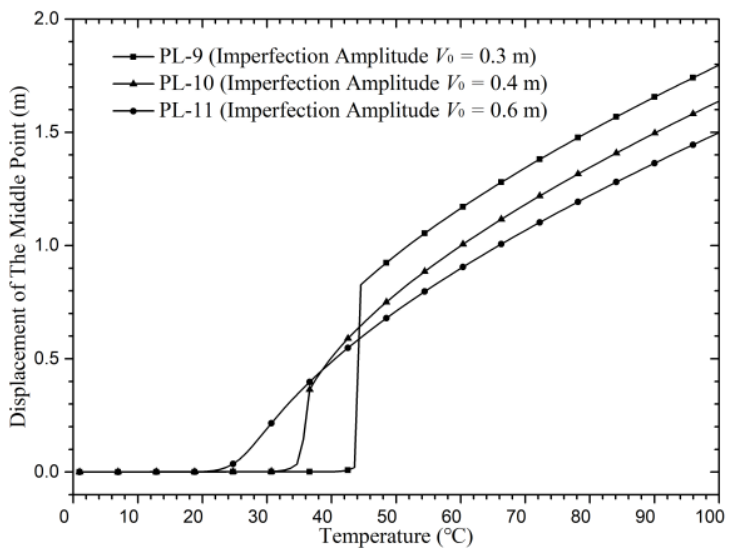

(d) Influenced by the imperfection amplitude

Fig. 20 Displacement of middle point changing with the temperature considering different factors

\section{Acknowledgement}

This research is partially supported by the National Natural Science Foundation of China (No. 52008410), the Basic and Applied Basic Research Foundation of Guangdong Province (No. 2019A1515110969), and the Natural Science Foundation of Guangdong Province (No. 2021A1515011734).

\section{References}

[1] Hong Z.H., Liu W.B. and Xu B.B., "Research on the pipeline walking caused by cyclic increasing soil friction for free deep-sea submarine pipelines laid on even seabed", Marine Structures, 75, 102873, 2021.

[2] Netto T.A. and Estefen S.F., "Buckle arrestors for deepwater pipelines", Marine Structures, 9(9), 873-883, 1996.

[3] Nielsen N.J.R., Lyngberg B. and Pedersen P.T., Upheaval buckling failures of insulated buried pipelines: a case story, Offshore Technology Conference, Houston, 1990.

[4] Guijt J., Upheaval buckling of offshore pipelines: overview and introduction, Offshore Technology Conference, Houston, 1990.

[5] Wang Z.K. and Heijden G.H.M., "Snap behaviour in the upheaval buckling of subsea pipelines under topographic step imperfection", Marine Structures, 69, 102674, 2020.

[6] Wang Z.K., Heijden G.H.M. and Tang Y.G., "Localised upheaval buckling of buried subsea pipelines", Marine Structures, 60, 165-185, 2018.

[7] Fernández-Valdés D., Vázquez-Hernández A.O., Ortega-Herrera J.A., Ocampo-Ramírez A. and Hernández D., "FEM-based evaluation of friction and initial imperfections effects on sandwich pipes local buckling", Marine Structures, 72, 102769, 2020.

[8] Terndrup Pedersen P. and Juncher Jensen J., "Upheaval creep of buried heated pipelines with initial imperfections", Marine Structures, 1, 11-12, 1988

[9] Wang F.C. and Han L.H., "Analytical behavior of carbon steel-concrete-stainless steel double-skin tube (DST) used in submarine pipeline structure", Marine Structures, 63, 99-116, 2019

[10] Wang Z.K., Tang Y.G. and Heijden G.H.M., "Analytical study of distributed buoyancy sections to control lateral thermal buckling of subsea pipelines", Marine Structures, 58, 199-222, 2018.

[11] Xu T., Lauridsen B. and Bai Y., "Wave-induced fatigue of multi-span pipelines", Marine Structures, 12, 83-106, 1999

[12] Maltby T.C. and Calladine C.R., "An investigation into upheaval buckling of buried pipelines - I. Experimental apparatus and some observations", International Journal of Mechanical Sciences, 37(9), 943-963, 1995

[13] Maltby T.C. and Calladine C.R., "An investigation into upheaval buckling of buried pipelines - II. Theory and analysis of experimental observations", International Journal of Mechanical Sciences, 37(9), 965-983, 1995.

[14] Taylor N. and Tran V., "Experimental and theoretical studies in subsea pipeline buckling", Marine Structures, 9, 211-257, 1996

[15] Armaghani D.J., Faizi K., Hajihassani M., Mohamad E.T. and Nazir R., "Effects of soil reinforcement on uplift resistance of buried pipeline", Measurement, 64, 57-63, 2015.

[16] Schaminee P., Zorn N. and Schotman G., Soil response for pipeline upheaval buckling analyses: full-scale laboratory tests and modelling, Offshore Technology Conference, Houston, 1990.

[17] Karampour H. and Albermani F., "Experimental and numerical investigations of buckle interaction in subsea pipelines", Engineering Structures, 66, 81-88, 2014. 
[18] Vazouras P., Tsatsis A. and Dakoulas P., "Thermal Upheaval Buckling of Buried Pipelines: Experimental Behavior and Numerical Modeling", Journal of Pipeline Systems Engineering and Practice, 12(1), 04020057, 2021.

[19] Hobbs R.E., "In-Service Buckling of Heated Pipelines", Journal of Transportation Engineering, 110(2), 175-189, 1984.

[20] Taylor N. and Gan A.B., "Submarine pipeline buckling-imperfection studies", Thin-Walled Structures, 4(4), 295-323, 1986.

[21] Ju G.T. and Kyriakides S., "Thermal buckling of offshore pipelines", Offshore Mechanics and Arctic Engineering, 110(4), 355-364, 1988.

[22] Ballet J.P. and Hobbs R.E., "Asymmetric effects of prop imperfections on the upheaval buckling of pipelines", Thin-Walled Structures, 13(5), 355-373, 1992.

[23] Wang Z.K., Tang Y.G., Yang J.G. and Soares G., "Analytical study of thermal upheaval buckling for free spanning pipelines", Ocean Engineering, 218, 108220, 2020.

[24] Palmer A., Ellinas C., Richards D. and Guijt J., Design of submarine pipelines against upheaval buckling, Offshore Technology Conference, Houston, 1990.

[25] Friedmann Y. and Debouvry B., "Analytical design method helps prevent buried pipe upheaval", Pipeline Industry, 75, 63-68, 1993.

[26] Bodaghi M. and Saidi A.R., "Levy-type solution for buckling analysis of thick functionally graded rectangular plates based on the higher-order shear deformation plate theory", Applied Mathematical Modelling, 34(11), 3659-3673, 2010.

[27] Bodaghi M. and Saidi A.R., "Buckling behavior of standing laminated Mindlin plates subjected to body force and vertical loading", Composite Structures, 93(2), 538-547, 2011.

[28] Bodaghi M. and Saidi A.R., "Thermoelastic buckling behavior of thick functionally graded rectangular plates", Archive of Applied Mechanics, 81(11), 1555-1572, 2011.

[29] Klever F.J., Van Helvoirt L.C. and Sluyterman A.C., A dedicated finite-element model for analyzing upheaval buckling response of submarine pipelines, Offshore Technology Conference, Houston, 1990.

[30] Zhang X.H. and Duan M.L., "Prediction of the upheaval buckling critical force for imperfect submarine pipelines", Ocean Engineering, 109, 330-343, 2015.

[31] Robert D.J. and Thusyanthan N.I., "Numerical and experimental study of uplift mobilization of buried pipelines in sands", Journal of Pipeline Systems Engineering and Practice, 6(1), 04014009,2015

[32] Xu L.G. and Lin M., "Numerical study on critical axial forces of upheaval buckling for initially stressed submarine pipelines on uneven seabed", Ocean Engineering, 145, 344-358, 2017.

[33] Chen Z.H., Yang J.G. and Wang Z.K., "Numerical study on upheaval buckling for surface laid subsea pipelines with topographic step imperfection", Applied Ocean Research, 101, laid subsea pipeli

[34] Liang Z., Lu X. and Zhang J., "Thermal vertical buckling of surface-laid submarine pipelines on a sunken seabed", Ocean Engineering, 173, 331-344, 2019.

[35] Stanisic D., Efthymiou M., Kimiaei M., and Zhao W.H., "Design loads and long term distribution of mooring line response of a large weathervaning vessel in a tropical cyclone environment", Marine Structures, 61, 361-80, 2018.

[36] Li X.Y., Wan J.H., Liu S.W. and Zhang L.M., "Numerical formulation and implementation of Euler-Bernoulli pile elements considering soil-structure-interaction responses", International Journal for Numerical and Analytical Methods in Geomechanics, 44, 1903-1925, 2020.

[37] Zeng X.G., Duan M.L. and Che X.Y., "Critical upheaval buckling forces of imperfect pipelines", Applied Ocean Research, 45, 33-39, 2014.

[38] Chen Z.H., Yang J.G. and Liu Z.S., "Experimental and numerical investigation on upheaval buckling of free-span submarine pipeline", Advanced Steel Construction, 15(4), 323-328, 2019. 